\title{
126 \\ The media contributed to the knowledge and decision making of patients throughout their cancer experiences
}

Balmer C. The information requirements of people with cancer: where to go after the "patient information leaflet"? Cancer Nurs 2005;28:36-44.

\section{Q How do patients with cancer use media-produced information? What is the impact of these sources on their cancer experiences?}

\section{DESIGN}

Qualitative study using Lincoln and Guba's naturalistic inquiry approach.

\section{SETTING}

Poole, UK.

\section{PATIENTS}

15 patients $(67 \%$ women, mean age 55 y) with cancer who had completed at least first line treatment.

\section{METHODS}

Loosely structured interviews (45-90 min) aimed at exploring sources of media-produced information accessed and avoided by people with cancer; why and how they are accessed; type of information sought; and the influence of the media on cancer patients. Interviews were tape recorded, transcribed, and analysed using constant comparison.

\section{MAIN FINDINGS}

4 categories were identified: (1) Looking beyond biomedicine. Despite feeling that they had little choice, almost all patients had faith in the information provided by most healthcare staff. Moreover, many believed that healthcare staff were responsible for disseminating information through accessible sources in the face of low levels of cancer awareness by the public. Media-produced information was a supplement to, rather than a replacement for, biomedical information and required endorsement by healthcare staff. Overall, patients used the media to inform decision making, clarify points, and promote discussion.

(2) Managing the search for media-produced information. Patients recognised that sensitivity to media information often did not occur until they became ill. Before diagnosis, information was in the form of "general knowledge." Most information seeking was done before initiation of treatment. Patients were reluctant to use information seeking to challenge decisions already made. Feeling unwell made accessing books and the internet difficult and modified patients' ability to access media such as television. After treatment, most patients intended to continue information seeking, citing the obligation to stay informed to help newly diagnosed patients. It was important that information be available from many sources and customised according to need.

(3) What is sought? Patients looked for particular types of information from the media. "Technical stuff" (about treatments and success rates) was least searched in the media and was perceived as under-reported. Patients were interested in "up and coming treatments" reported in the media, and the internet was the source of choice for some seeking more indepth information. In response to the perceived inadequacies of hospital-produced information, many patients sought information about "life stuff" (ie, practical and emotional advice on living with cancer) from the media. "Other

For correspondence: Ms C Balmer, Dorset Cancer Centre, Poole Hospital, Poole, UK. claire.balmer@poole.nhs.uk

Source of funding: no external funding. peoples' stories" about cancer experiences were frequently sought and seen as useful even if they were not applicable to their own situations.

(4) The media hierarchy. The internet was consistently viewed as the most trustworthy source and was seen as more relevant than books. The usefulness of print media was mediated by perceived journalistic bias and financial incentives. Broadsheet newspapers were seen as more "truthful" than tabloids. The emotive value of soap operas was recognised and viewed as "melodramatic," "superficial," and the least reliable option.

\section{CONCLUSIONS}

Throughout their cancer experiences, patients used the media to contribute to knowledge and decision making. Interpretation of the media depended on patients' individual needs or their rating of the media source. Use of media-produced information was constrained by the physical inability to access sources at certain points in the disease course. The internet was seen as the most trustworthy source.

\section{Commentary}

The experience of cancer can leave patients feeling helpless, frightened, and out of control. The value of comprehensive and relevant information in helping patients to cope and regain a sense of control is well recognised. ' However, provision of such information can be erratic, fail to meet patient need, and diminish active involvement in decision making. ${ }^{2}$

The study by Balmer adds to a growing literature on patient information by specifically exploring the perspectives of those who attempt to make sense of living with cancer. Balmer shows how patients used various media, such as written articles, television programmes, and the internet, to access a range of topics related to their illnesses. Balmer's preliminary work supplements our understanding of the information patients find useful at varying stages of their cancer journey. It also highlights the process by which patients seek such information. The findings presented are congruent with those of other studies, particularly regarding the motivations of patients with cancer to use the internet to verify medical evidence, gain psychological support, and cope with loneliness. $^{3}$

Overall, the study by Balmer highlights the need for practitioners to be more aware of the effects of patients' increasing use of media that are not quality assured to gain information and make decisions about their care and support. Because healthcare professionals cannot control all information available in a therapeutic relationship, established patterns of communication in practitioner-patient relationships could be challenged, although ultimately they may become more equal.

$$
\text { Helen Roberts, RGN, MSc, PGDipled) }
$$

University of York

York, UK

1 Roberts D. Cancer care. In: Regel S, Roberts D. Mental health liaison: a handbook for health care professionals. London: Bailliere Tindall, 2002.

2 Coulter A, Entwistle V, Gilbert D. Sharing decisions with patients: is the information good enough? BMJ 1999;318:318-22.

3 Ziebland S, Chapple A, Dumelow C, et al. How the internet affects patients' experience of cancer: a qualitative study. BMJ 2004;328:564-7. 